\title{
IL-3 promotes the development of experimental autoimmune encephalitis
}

\author{
Kerstin Renner, ${ }^{1}$ Sonja Hellerbrand, ${ }^{1}$ Fabian Hermann, ${ }^{1}$ Christine Riedhammer, ${ }^{2}$ Yvonne Talke, ${ }^{1}$ \\ Gabriela Schiechl, ${ }^{1}$ Manuel Rodriguez Gomez, ${ }^{1}$ Simone Kutzi,, ${ }^{1}$ Dagmar Halbritter, ${ }^{2}$ Nicole Goebel, ${ }^{1}$ \\ Hilke Brühl, ${ }^{3}$ Robert Weissert, ${ }^{2,4}$ and Matthias Mack ${ }^{1,4}$ \\ 'Department of Internal Medicine II - Nephrology, ${ }^{2}$ Department of Neurology, ${ }^{3}$ Department of Internal Medicine I, \\ University Hospital Regensburg, Regensburg, Germany. ${ }^{4}$ Regensburg Center for Interventional Immunology, \\ Regensburg, Germany.
}

Little is known about the role of IL-3 in multiple sclerosis (MS) in humans and in experimental autoimmune encephalomyelitis (EAE). Using myelin oligodendrocyte glycoprotein (MOC) peptideinduced EAE, we show that CD4 ${ }^{+} \mathrm{T}$ cells are the main source of IL-3 and that cerebral IL-3 expression correlates with the influx of T cells into the brain. Blockade of IL-3 with monoclonal antibodies, analysis of IL-3 deficient mice, and adoptive transfer of leukocytes demonstrate that IL-3 plays an important role for development of clinical symptoms of EAE, for migration of leukocytes into the brain, and for cerebral expression of adhesion molecules and chemokines. In contrast, injection of recombinant IL-3 exacerbates EAE symptoms and cerebral inflammation. In patients with relapsingremitting MS (RRMS), IL-3 expression by T cells is markedly upregulated during episodes of relapse. Our data indicate that IL-3 plays an important role in EAE and may represent a new target for treatment of MS.

Authorship note: RW and MM are co-senior authors.

Conflict of interest: The authors have declared that no conflict of interest exists.

Submitted: February 17, 2016 Accepted: August 25, 2016 Published: October 6, 2016

Reference information: JCI Insight. 2016;1(16):e87157. doi:10.1172/jici.nsight.87157.

\section{Introduction}

Little is known about the role of IL-3 in multiple sclerosis (MS) in humans and in murine or rat experimental autoimmune encephalomyelitis (EAE), the animal model of MS. In C57BL/6 (H-2 ${ }^{\mathrm{b}}$ ) mice with myelin oligodendrocyte glycoprotein (MOG) peptide 35-55-induced EAE, production of IL-3 was found after specific restimulation of total leukocytes from lymph nodes, CNS, blood, and spleen (1). IL-3 was also a prominent cytokine produced by $\mathrm{CD}^{+} \mathrm{T}$ cells in SJL/J (H-2 $\left.{ }^{\mathrm{s}}\right)$ mice immunized with PLP peptide 139-151 (2) and in the spinal cords of IFN- $\gamma^{-1-} \mathrm{C} 57 \mathrm{BL} / 6\left(\mathrm{H}-2^{b}\right)$ mice immunized with bovine myelin basic protein (MBP) (3). After adoptive transfer of an encephalitogenic T cell clone into SJL/J (H-2 $)$ mice and in a model of Semliki Forest virus A7(74)-induced demyelination, IL-3 expression was upregulated in the CNS (4, 5). It was also shown that IL-3 induced proliferation of a mouse microglia cell line (6).

IL-3 belongs to the family of hematopoietic cytokines with 4 short $\alpha$-helices that also includes GM-CSF and IL-5 (7). All 3 cytokines bind to specific $\alpha$-receptor subunits but use a common $\beta$-receptor subunit for signal transduction, mainly via the JAK/STAT pathway (7). IL-3 is primarily produced by activated T cells (8) but can also be expressed by innate response activator B cells (9), basophils, neurons, and microglial cells (10-13). IL-3 induces activation and/or increases the survival of various target cells, including mast cells, basophils, monocytes, DCs, B cells, T cells, and endothelial cells (14-21). An important role of IL-3 in inflammation and autoimmunity was recently shown in a model of sepsis (9), as well as in models of arthritis and lupus nephritis $(22,23)$. IL-3 increases the release of monocytes and neutrophils from the BM, activates monocytes and BM cells to release proinflammatory cytokines, has antiapoptotic effects on various leukocytes, and activates endothelial cells to upregulate E- and P-selectin (9, 14-21).

In humans, transcriptional analysis of cytokine expression in brain specimens from MS-patients and healthy controls showed upregulation of IL-3 expression in MS-lesions (24). IL-3 expression by mononuclear cells was found to be either downregulated or upregulated in MS-patients compared with controls $(25,26)$. MS-patients treated with the copolymer PI-2301 showed upregulation of serum IL-3 levels (27).

So far, the role of IL-3 for development of EAE has not been analyzed and no experiments have been performed to study the role of IL-3 in encephalitis by inhibition or KO of IL-3. Overexpression of IL-3 in astrocytes resulted in macrophage/microglial-mediated primary demyelination and motor disease with white 
A

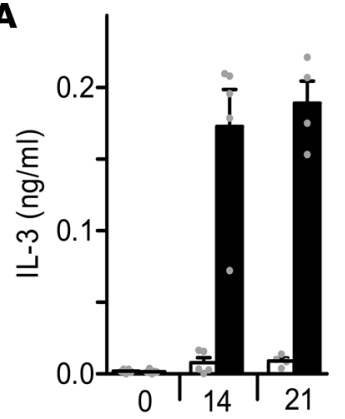

Days after EAE induction

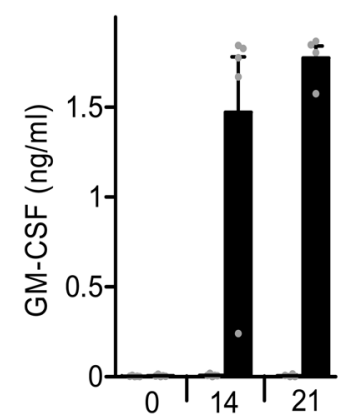

Days after EAE induction

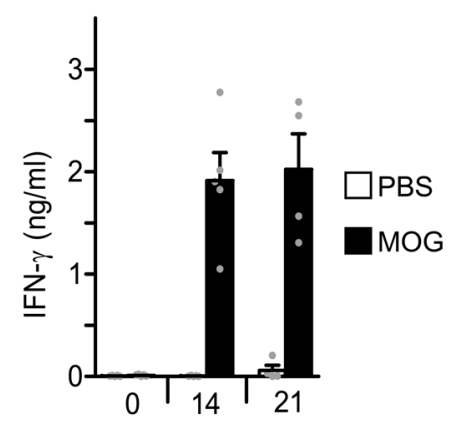

Days after EAE induction

B
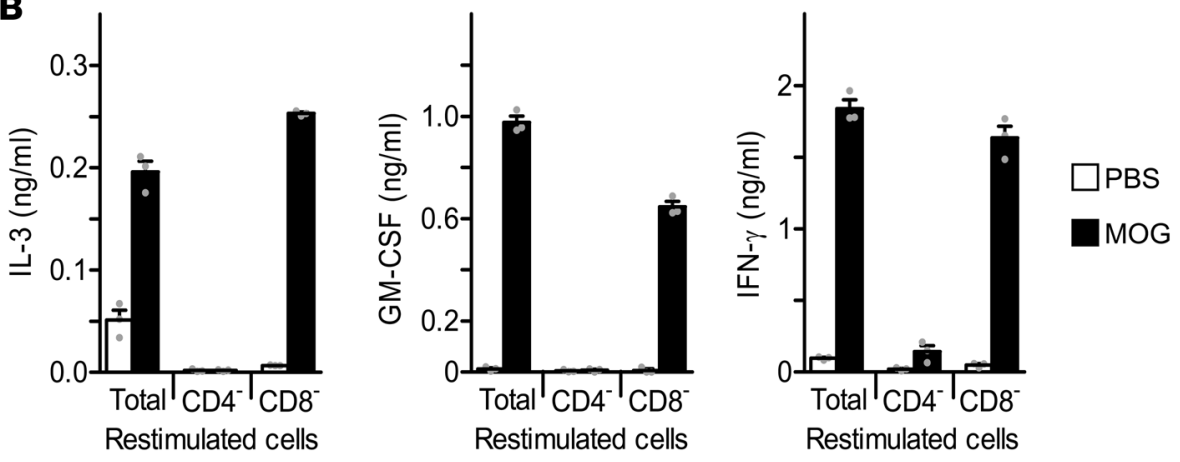

C
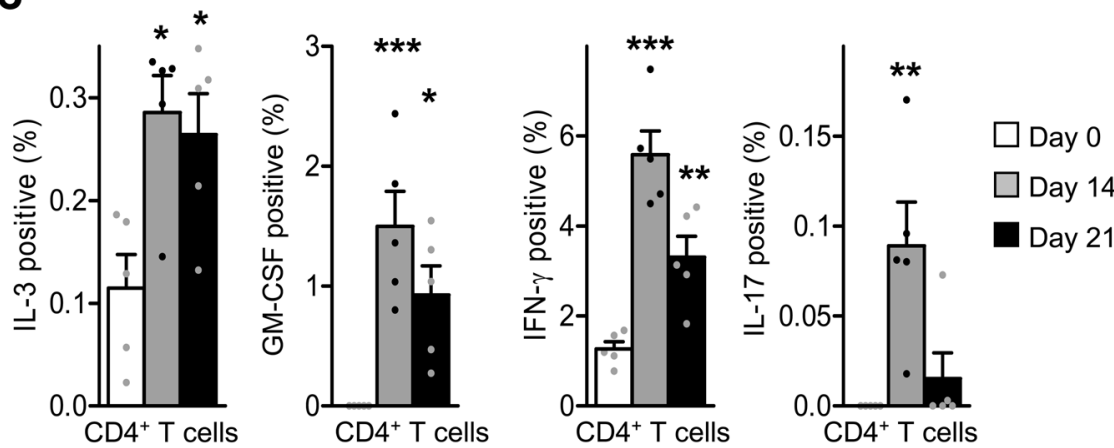

Figure 1. MOG-specific expression of IL-3 by CD4 ${ }^{+}$T cells. C57BL/ $6\left(\mathrm{H}-2^{\mathrm{b}}\right)$ mice were immunized with MOG peptide 35-55 on day 0 . (A) Immediately before immunization (day 0 ) or 14 and 21 days after immunization (4-5 mice/ time point), splenocytes were restimulated with MOC peptide 35-55 or PBS as control for 3 days, and the levels of IL-3, GM-CSF, and IFN- $\gamma$ were measured in the supernatant. A pronounced MOC peptide 35-55-specific release of IL-3, GM-CSF, and IFN- $\gamma$ was detectable 14 and 21 days after immunization. (B) Splenocytes obtained at day 14 after immunization were depleted of $\mathrm{CD} 4^{+}$or $\mathrm{CD} 8^{+} \mathrm{T}$ cells and restimulated with MOC peptide or PBS (3 mice/group). The MOG-specific release of IL-3 and GM-CSF was completely dependent on the presence of $\mathrm{CD} 4^{+} \mathrm{T}$ cells. (C) Before immunization (day 0) or 14 and 21 days after immunization, splenocytes were activated with PMA and ionomycin for 4 hours and stained for intracellular expression of IL-3, CM-CSF, IFN- $\gamma$, and IL-17 (5 mice/time point). The frequency of cytokine-positive CD4 ${ }^{+} \mathrm{T}$ cells markedly increased after immunization. One out of 2 representative experiments is shown. Data are represented as mean \pm SEM, one-way ANOVA test of day 14 or day $21 \mathrm{vs}$. day $0:{ }^{*} P \leq 0.05,{ }^{* *} P \leq$ $0.01,{ }^{* *} P<0.001$.

matter lesions (28). Transgenic overexpression of IL-3 led to a motor neuron disease and muscular atrophy with autoimmunity against motor neurons (29). In addition, a positive correlation was described between MBP-specific production of IL-3 by T cells and the encephalitogenic potential of these cells (30). On the other hand, transgenic expression of antisense IL-3 mRNA resulted in development of neurological dysfunction in 3 of 5 founder animals (31), and IL-3 was described as trophic factor for cholinergic neurons (32).

We have analyzed the role of IL-3 in MOG peptide 35-55-induced EAE in C57BL/6 (H-2 $2^{b}$ mice using a blocking monoclonal antibody against IL-3, IL-3 deficient mice, and injection of recombinant murine IL-3. We show that IL-3 is required for migration of leukocytes into the CNS but not for development of the immune response against MOG peptide. Blockade of IL-3 or genetic deficiency of IL-3 improved development of EAE, while injection of recombinant murine IL-3 exacerbated EAE and cerebral inflammation. In patients with relapsing-remitting MS (RRMS), a marked upregulation of IL-3 production by T cells was found during episodes of relapse.

\section{Results}

Analysis of IL-3 expression in EAE. EAE was induced in C57BL/6 $\left(\mathrm{H}-2^{\mathrm{b}}\right)$ mice by immunization with MOG peptide 35-55, as described in the Methods section. We analyzed expression of IL-3 in the spleen and CNS before immunization with MOG peptide 35-55 (day 0), as well as 14 and 21 days after immunization. The MOG peptide 35-55-specific release of cytokines was measured by restimulation of splenocytes with MOG peptide 35-55 (Figure 1A and Supplemental Figure 1; supplemental material available online with this article; doi:10.1172/jci. insight.87157DS1). In nonimmunized mice, no MOG-specific release of IL-3, IFN- $\gamma$, GM-CSF, or IL-17 was detectable, while considerable amounts of these cytokines were released 14 and 21 days after immunization. To identify which cells are responsible for the MOG peptide 35-55-induced release of IL-3, we depleted CD4 ${ }^{+}$ or $\mathrm{CD}^{+} \mathrm{T}$ cells with magnetic beads and restimulated the remaining splenocytes with MOG peptide 35-55. 
A

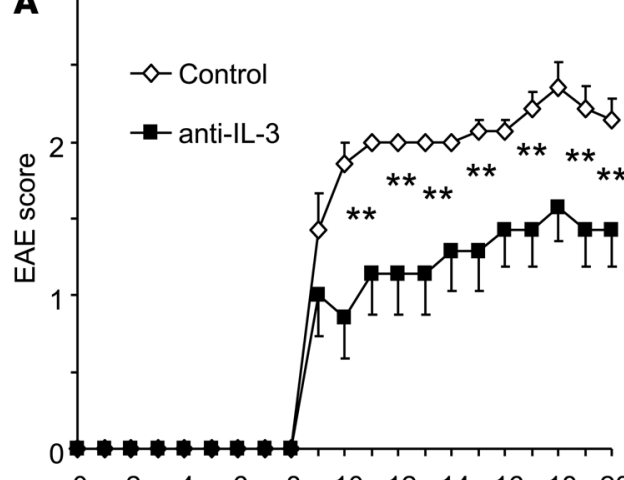

$\begin{array}{lllllllllll}0 & 2 & 4 & 6 & 8 & 10 & 12 & 14 & 16 & 18 & 20\end{array}$

Days after immunization with MOG-peptide

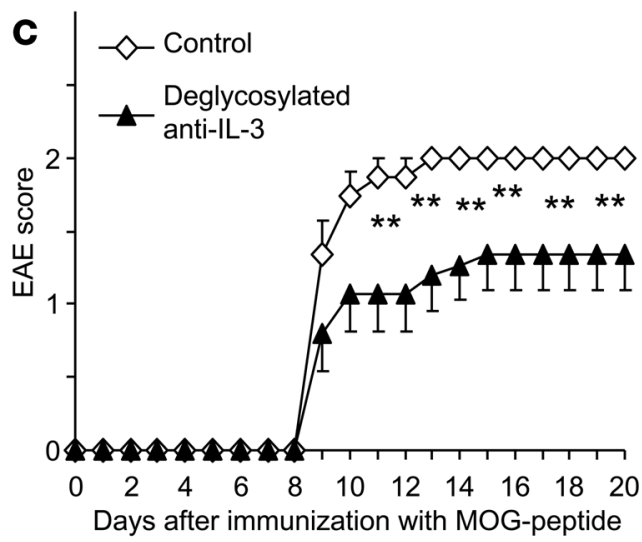

$\mathbf{E}$
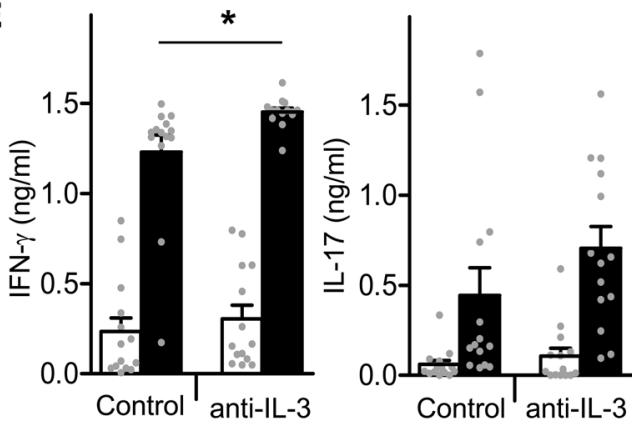

B
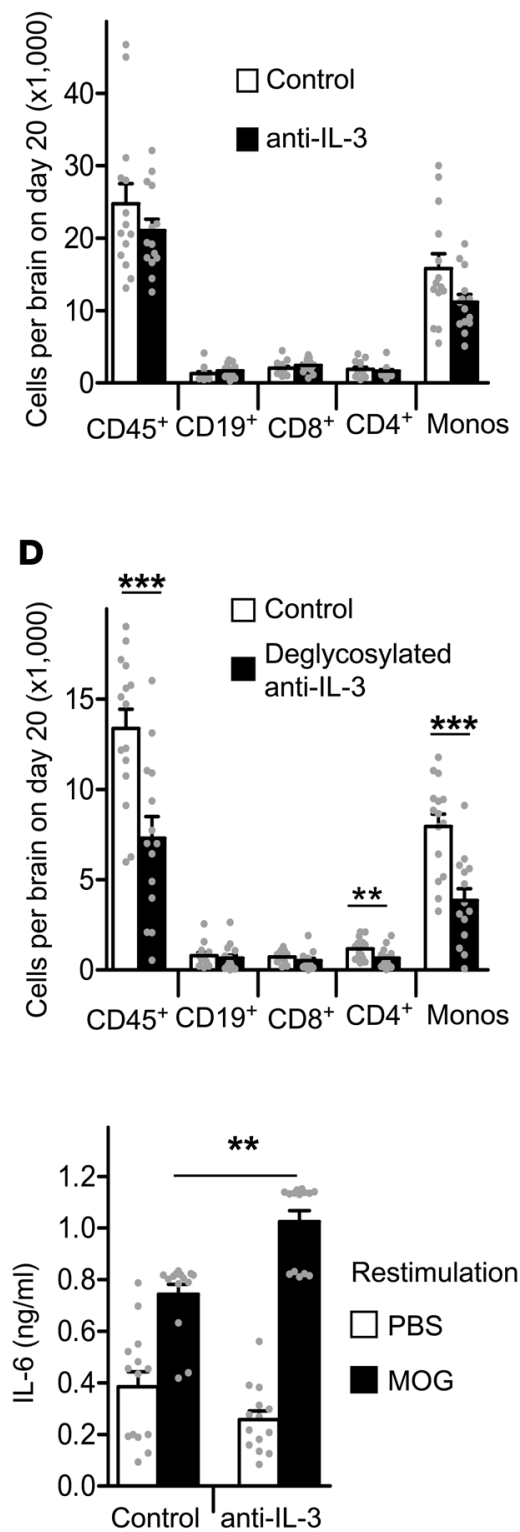

Figure 2. Blockade of IL-3 reduces development of EAE. EAE was induced in C57BL/6 mice by immunization with MOC peptide 35-55 on day 0 . From day $0-19$, mice were treated with an intact or deglycosylated neutralizing anti-IL-3 antibody (anti-IL-3, $50 \mu \mathrm{g} /$ day) or purified rat IgC (Control, $50 \mu \mathrm{g} /$ day) ( $n=14-15$ / group). (A and $\mathbf{C}$ ) Clinical symptoms of EAE (EAE score) were significantly ameliorated ( $P$ $<0.01$ ) in anti-IL-3-treated mice. (B and $\mathbf{D}$ ) Leukocytes infiltrating the brain were quantified by flow cytometry on day 20. Monocytes (Monos) and total leukocytes (CD45+) were reduced by blockade of IL-3, while infiltrating $\mathrm{CD}^{+} \mathrm{T}$ cells, $\mathrm{CD} 8^{+} \mathrm{T}$ cells, and $\mathrm{CD} 19^{+} \mathrm{B}$ cells were not different between the groups. (E) On day 20 , splenocytes were restimulated with MOC peptide $35-55$ or PBS as control for 3 days, and the levels of IFN- $\gamma$, IL-6, and IL-17 were measured in the supernatant by ELISA. One out of 2 representative experiments is shown. Data are represented as mean \pm SEM, Student's $t$ test of control vs. anti-IL-3: ${ }^{*} P \leq 0.05,{ }^{* *} P<$ $0.01,{ }^{* *} P<0.001$

Depletion of $\mathrm{CD}^{+} \mathrm{T}$ cells completely abrogated the MOG-induced 35-55 release of IL-3, IFN- $\gamma$, GM-CSF, and IL-17, while depletion of $\mathrm{CD}^{+} \mathrm{T}$ cells had little effect (Figure 1B and Supplemental Figure 1). This shows that MOG-specific $\mathrm{CD}^{+} \mathrm{T}$ cells are the main source of IL-3 and other cytokines among splenocytes from EAE mice. To directly visualize cytokine expression by $\mathrm{CD}^{+} \mathrm{T}$ cells, we performed intracellular cytokine staining. The frequency of $\mathrm{CD}^{+}$ $\mathrm{T}$ cells expressing IL- 3 , IFN- $\gamma$, GM-CSF, and IL-17 markedly increased from day 0 to day 14 after immunization with some decline on day 21 (Figure 1C). Costaining of IL-3, IFN- $\gamma$, GM-CSF, and IL-17 reveals that there is no clear coexpression of IL-3 with IFN- $\gamma$, GM-CSF, and IL-17 (Supplemental Figure 1).

We next quantified the expression of IL-3 in the spinal cord and the cerebral infiltration of leukocytes. From day 0 to day 14 , a marked influx of monocytes, CD4 ${ }^{+} \mathrm{T}$ cells, CD8 ${ }^{+} \mathrm{T}$ cells, and $\mathrm{B}$ cells occurred in the CNS (Supplemental Figure 2). The number of infiltrating monocytes was much higher than the number of infiltrating $\mathrm{T}$ and $\mathrm{B}$ cells. Interestingly, on day $21, \mathrm{~T}$ and $\mathrm{B}$ cells almost completely disappeared, while monocytes remained high in the CNS (Supplemental Figure 2A). Parallel to the infiltration of T cells, expression of IL-3, GM-CSF, IL-17, and IFN- $\gamma$ markedly increased in the spinal cord from day 0 to day 14 but declined almost to background levels on day 21, suggesting that most of the IL-3 expression in the CNS originates from infiltrating T cells (Supplemental Figure 2B).

Taken together, our data show that MOG-specific $\mathrm{CD}^{+} \mathrm{T}$ cells are the main producers of IL-3. Peak expression of IL-3 in the brain occurs at about 14 days after immunization and correlates with the cerebral influx of $\mathrm{T}$ cells.

Improvement of EAE by blockade of IL-3. IL-3 was neutralized by daily i.p. injection of a blocking antibody against IL-3. Treatment of mice was started immediately after immunization with MOG peptide 35-55 (day 0) and continued until day 19. Clinical symptoms of EAE were evaluated in a blinded manner 

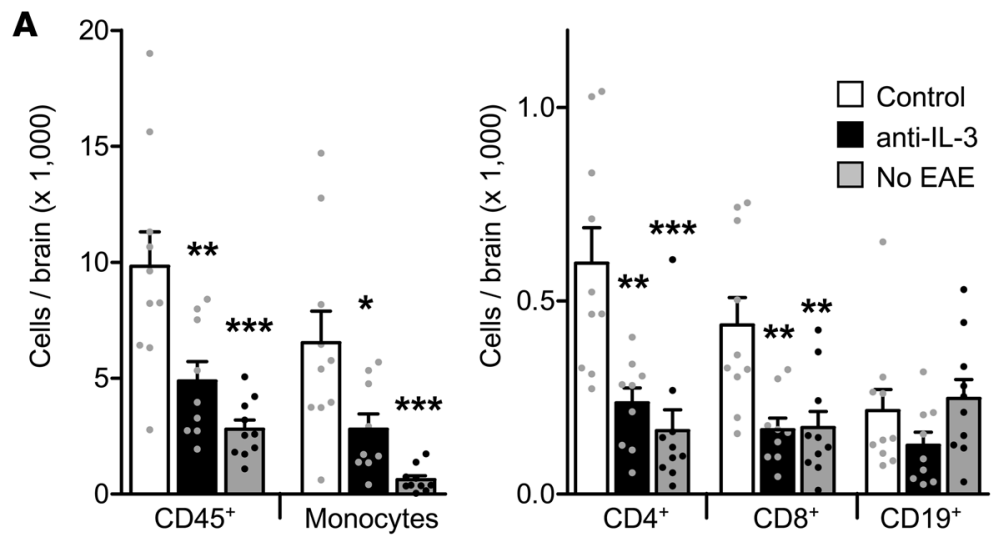

B
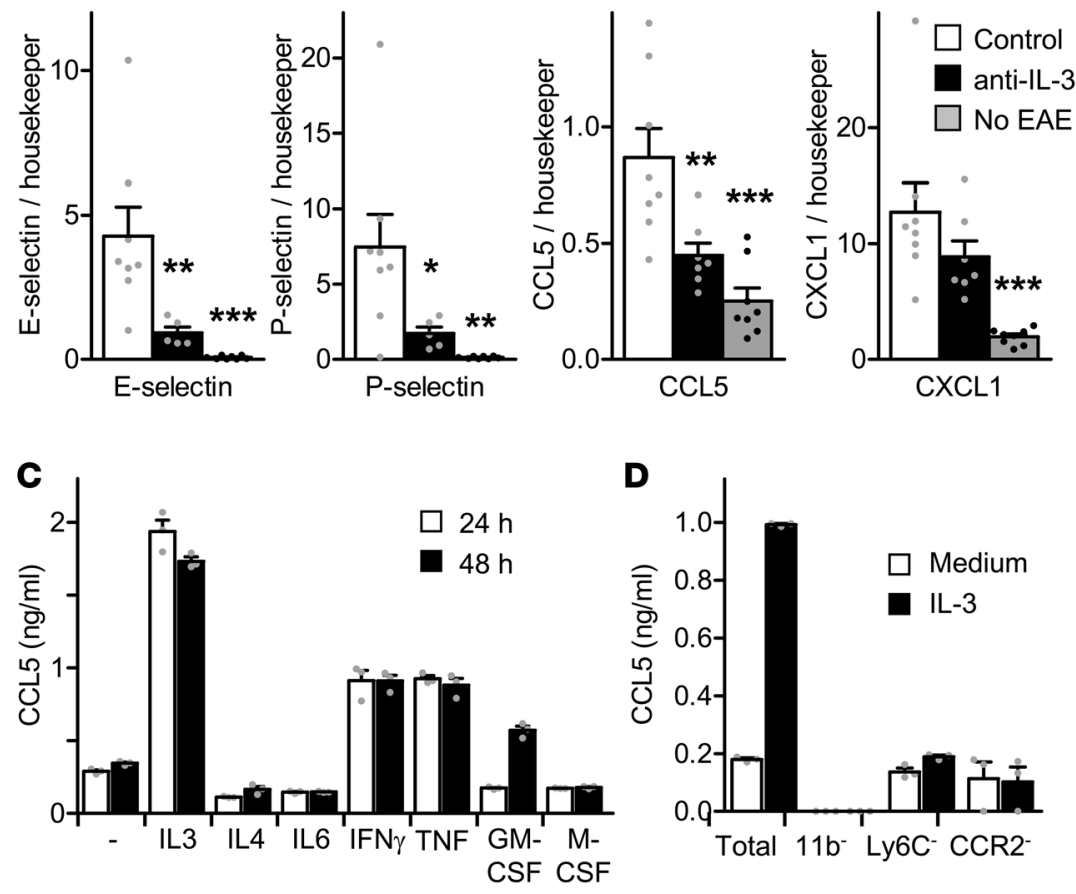
of IL-3 resulted in a highly significant reduction of EAE symptoms from day 10 throughout day 20 (Figure 2A) and reduced the overall incidence of EAE (Supplemental Figure 3). On day 21, we quantified the infiltrating cells in the brain by flow cytometry. Consistent with the time course above, numbers of cerebral $\mathrm{T}$ and $\mathrm{B}$ cells were low in both groups. However, monocytes were detectable at considerable numbers and were reduced by about $35 \%$ in the anti-IL-3 group (Figure 2B). Also, a deglycosylated variant of the anti-IL-3 antibody achieved a highly significant inhibition of EAE symptoms and reduced the infiltration of the brain with monocytes, indicating that blockade of IL-3 is sufficient to limit EAE severity, while depletion of IL-3 (e.g., via Fc-receptor-positive cells) does not contribute to the beneficial effects of the IL-3 antibody (Figure 2, C and D). Restimulation of splenocytes with MOG peptide 35-55 was performed to quantify the cellular immune response against MOG. The MOG-specific release of IFN- $\gamma$, IL-17, or IL-6 was not reduced in mice treated with anti-IL-3, indicating that blockade of IL-3 does not interfere with the efficacy of immunization and the cellular immune response against MOG (Figure 2E).

Inhibition of cerebral influx of $T$ cells and monocytes by blockade of $I L-3$. EAE symptoms rapidly develop within 9-12 days after immunization with MOG peptide 35-55 in close correlation with the cerebral influx of monocytes and T cells. We therefore blocked IL-3 from day 0 to day 10 after immunization with MOG and analyzed the cerebral infiltrate on day 11. As control, we also included healthy untreated WT mice. In MOG-immunized mice, blockade of IL-3 markedly reduced the cerebral influx of $\mathrm{CD} 4^{+} \mathrm{T}$ cells, $\mathrm{CD} 8^{+} \mathrm{T}$ cells, B cells, and monocytes (Figure 3A). In the anti-IL-3 group, the number of infiltrating T cells in the brain was reduced almost to the level of healthy controls, and the number of monocytes in the brain was reduced by more than $50 \%$. To investigate whether leukocyte infiltration in the brain differs from that in the spinal cord, we analyzed both compartments in control and anti-IL-3-treated mice on day 13 after immunization with MOG peptide (Supplemental Figure 4). In accordance with published data (33), the immune cell infiltrates were similar in the brain and spinal cord, and blockade of IL-3 reduced cell infiltrates in both 

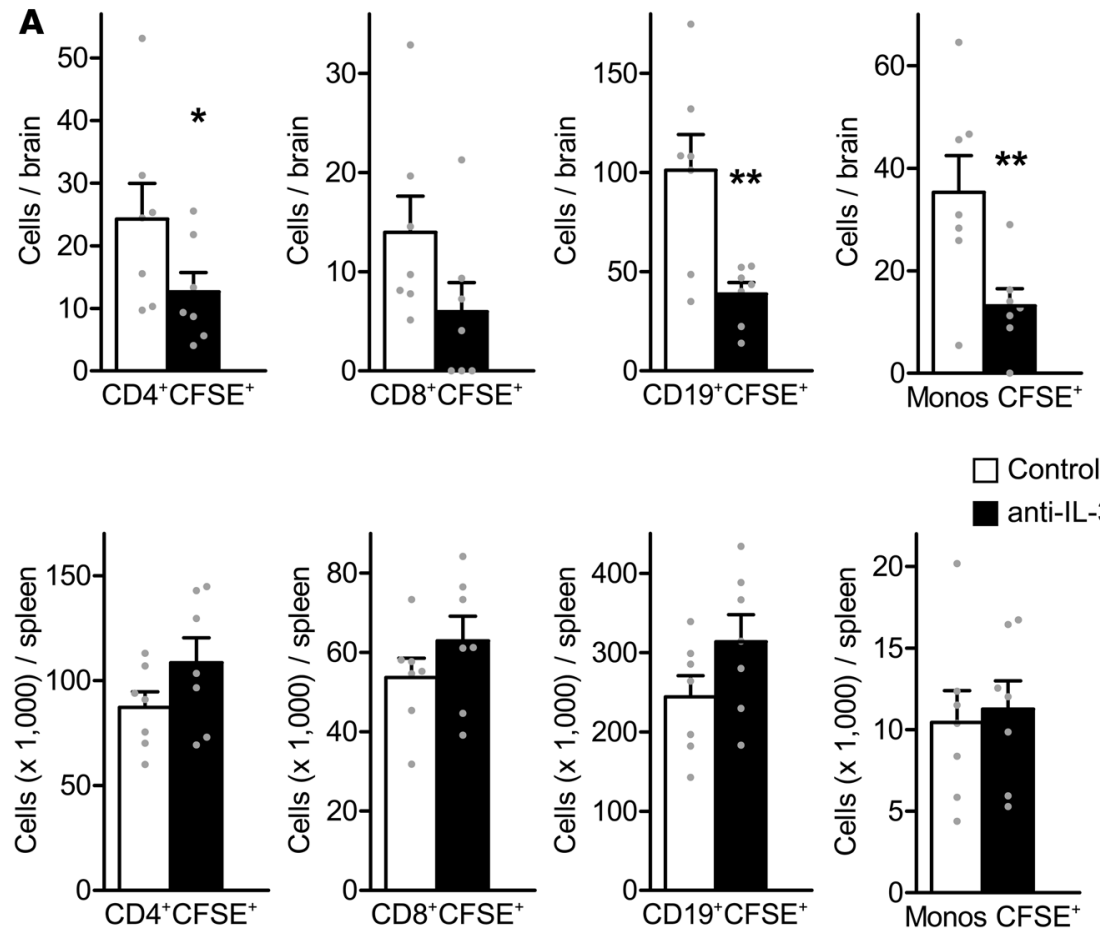

B

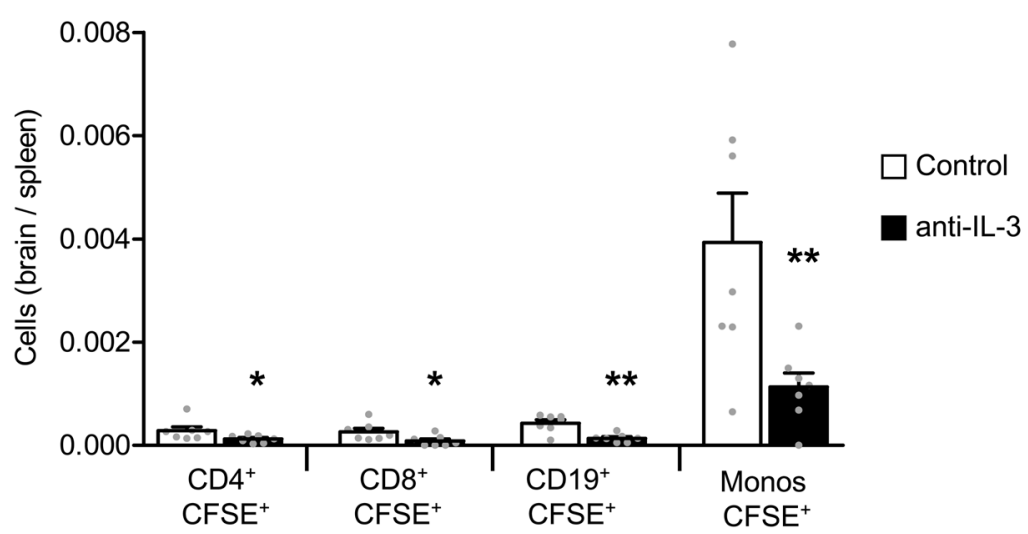

Figure 4. Adoptive transfer of CFSE-labeled leukocytes into mice with incipient EAE. C57BL/6 $\left(\mathrm{H}-2^{\mathrm{b}}\right)$ mice were immunized with MOC peptide 35-55 on day 0 and treated from day $0-12$ with a neutralizing anti-IL-3 antibody (anti-IL-3, $50 \mu \mathrm{g} /$ day) or purified rat IgC (Control, $50 \mu \mathrm{g} /$ day) $(n=7 /$ group). On day 11, CFSE-labeled splenocytes were i.v. injected. These splenocytes were obtained on day 11 from $\mathrm{C57BL} / 6\left(\mathrm{H}-2^{\mathrm{b}}\right)$ mice that were immunized with MOC peptide 35-55 on day 0 but not treated with mAbs. (A) Quantification of CFSE-labeled leukocytes in the brain and the spleen of recipients on day 13 . Blockade of IL-3 significantly reduced the number of infiltrating CFSE $^{+}$ $T$ cells, B cells, and monocytes in the brain but not in the spleen. (B) Ratio of CFSE-labeled leukocytes detected within the brain and within the spleen. Monocytes migrated much more efficiently into the brain than T and B cells. Data are represented as mean $\pm \mathrm{SEM}$, Student's $t$ test of anti-IL-3 vs. Control: ${ }^{*} P \leq 0.05,{ }^{* *} P<0.01$

compartments by about $50 \%$. By real-time PCR, we quantified expression of E-selectin, P-selectin, CCL5 (RANTES), and CXCL1 in the brain, which are known to be important for the migration of leukocytes into the brain (34-37). Blockade of IL-3 reduced the cerebral expression of $\mathrm{E}$ - and P-selectin by more than $70 \%$ and the expression of CCL5 (RANTES) by about $50 \%$, while expression of CXCL1 was not significantly changed (Figure 3B). To further investigate the impact of IL-3 on the release of CCL5, we cultured splenocytes from C57BL/6 $\left(\mathrm{H}^{\mathrm{b}}{ }^{\mathrm{b}}\right)$ mice with IL-3 and measured the production of CCL5. Among a variety of cytokines - including IFN- $\gamma$, TNF, and GM-CSF - IL-3 induced the strongest release of CCL5, while IL-4, IL-6, and M-CSF were ineffective (Figure $3 C)$. Depletion of leukocytes subsets from isolated splenocytes was used to identify the IL-3 target cells. Most of the IL-3-induced release of CCL5 is derived from $\mathrm{CD} 11 \mathrm{~b}^{+} \mathrm{Ly} 6 \mathrm{C}^{+} \mathrm{CCR} 2^{+}$monocytes, since depletion of these cells almost completely abrogated the release of CCL5 (Figure 3D).

To demonstrate the importance of IL-3 for migration of leukocytes into the brain and to exclude that blockade of IL-3 interferes with the immune response against MOG, we adoptively transferred CFSE-labeled splenocytes that were obtained from mice 11 days after immunization with MOG peptide 35-55. The donor mice were not treated with anti-IL-3 antibodies. Recipients were immunized with MOG peptide 35-55, treated daily with anti-IL-3 or rat IgG from day 0-12, and received CFSE-labeled splenocytes on day 11. On day 13, we quantified the number of CFSE-labeled leukocytes in the brain and the spleen. In this experimental setup, the migration of adoptively transferred CFSE-labeled leukocytes is independent of their peripheral priming or activation. Blockade of IL-3 markedly reduced the migration of leukoctes into the CNS (71\% reduction for monocytes, $56 \%$ and $68 \%$ reduction for $\mathrm{CD}^{+}$and $\mathrm{CD}^{+} \mathrm{T}$ cells, and $68 \%$ reduction for B cells) (Figure $4 \mathrm{~A}$ ). The migration of CFSE-labeled leukocytes into the spleen was not reduced. We also calculated the ratio of CFSE-labeled cells in the CNS and spleen to control for possible variations in the number of effectively transferred cells and to find out whether leukocyte subsets differ in their ability to migrate into the brain. Interestingly, monocytes migrated about 10 times more 

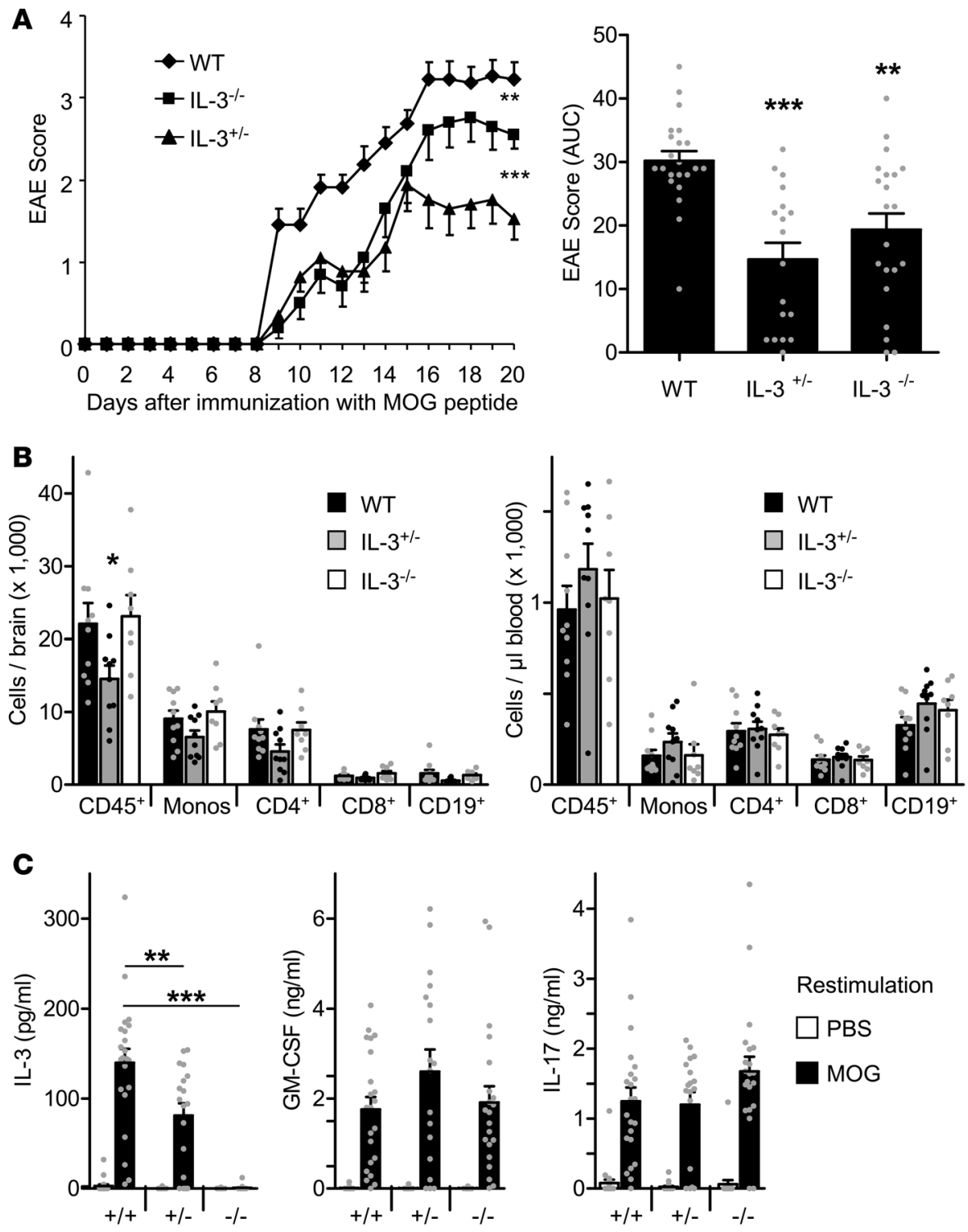

Figure 5. Reduced development of EAE in IL-3-deficient mice. EAE was induced in C57BL/6 WT mice (IL-3 $3^{+++}, n=22$ ), heterozygous IL-3-deficient mice (IL-3 $\left.3^{+-}, n=18\right)$, and homozygous IL-3-deficient mice (IL-3/-, $n=$ 21) by immunization with MOC peptide $35-55$ on day 0 . (A) Clinical symptoms of EAE (EAE score) were significantly diminished in $\mathrm{IL}^{-3^{+/}}$ and $\mathrm{IL}-3^{-1-}$ mice, as seen by daily monitoring and by added scores (AUC). Pooled data of 2 independent experiments are shown. (B) Leukocytes were quantified in the brain and in the peripheral blood by flow cytometry on day 20 ( $n=8-10 /$ group). (C) On day 20 , splenocytes were restimulated with MOC peptide 35-55 or PBS for 3 days, and the release of IL-3, GM-CSF, and IL-17 was measured in the supernatant by ELISA. Data are represented as mean \pm SEM, one-way ANOVA test of $\mathrm{IL}^{-3^{+/}}$ or IL-3-/- vs. IL-3 $3^{+/+}:{ }^{*} P \leq 0.05,{ }^{* *} P<0.01,{ }^{* *} P$ $<0.001$.

efficiently into the brain than $\mathrm{T}$ cells and B cells (Figure 4B). Blockade of IL-3 significantly reduced the migration of leukocytes into the brain.

Reduced development of EAE in IL-3-deficient mice. IL-3-deficient mice were backcrossed for 6 generations on a C57BL/6 background. Heterozygous IL-3-deficient mice were crossbred to generate WT, heterozygous $\left(\mathrm{IL}-3^{+/-}\right.$), and homozygous (IL-3 $3^{-/}$) IL-3-deficient littermates. Female 8- to 12 -week-old mice were immunized with MOG peptide $35-55$ on day 0 and monitored until day 20. Heterozygous $(n=18)$ and homozygous $(n=21)$ IL-3deficient mice developed significantly less symptoms of EAE than WT animals ( $n$ = 22) (Figure 5A). There was no significant difference between heterozygous and

homozygous IL-3-deficient mice in the overall score (AUC); however, from day 17-20, heterozygous mice showed lower EAE scores than homozygous mice. Counter-regulatory mechanisms in homozygous mice, as seen by an increased MOG-specific release of IL-17 in IL- $3^{-/}$mice, may account for this unexpected finding (Figure 5C). Leukocyte subpopulations infiltrating the brain were analyzed in comparison with the peripheral blood on day 20. Consistent with the clinical EAE score, cerebral infiltration of monocytes, T cells, and B cells was significantly reduced in heterozygous mice, while there was no reduction in homozygous mice. In the peripheral blood, only $\mathrm{CD} 19^{+} \mathrm{B}$ cells showed a significant but small increase in heterozygous mice (Figure 5B). Splenocytes were restimulated with MOG peptide 35-55 for 3 days to measure the MOG-specific release of IL-3, GM-CSF, and IL-17 in the supernatant by ELISA (Figure 5C). The release of IL-3 was significantly reduced in heterozygous and completely abrogated in homozygous IL-3-deficient mice. The release of GM-CSF was unchanged, and the release of IL-17 was significantly higher in homozygous mice. Leukocyte infiltration in the brain, cerebral expression of chemokines and selectins, and the MOG-specific immune response were also studied in IL-3 $3^{+/+}$, IL-3 $3^{+/}$, and IL-3 $3^{-/}$littermates on day 11 after immunization with MOG peptide (Supplemental Figure 5). Infiltration of monocytes, T and B cells, and cerebral expression of CCL2 and CCL5 were reduced in IL- $3^{+/-}$and IL- $3^{-/-}$mice on day 11. Expression of E- and P-selectin was only reduced in IL-3 $3^{-/}$mice. The MOG-specific release of IL-17 was significantly increased in IL-3 $3^{+/}$and IL- $3^{-/-}$ mice, while the release of GM-CSF was unchanged and the release of IL-3 was reduced or absent, as expected 
A

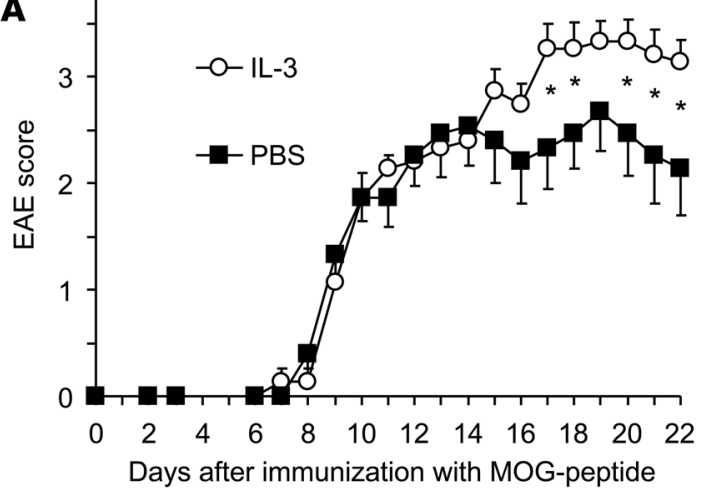

Figure 6. Injection of recombinant IL-3 exacerbates development of EAE. EAE was induced in $\mathrm{C57 \textrm {BL } / 6}\left(\mathrm{H}-\mathrm{2}^{\mathrm{b}}\right)$ mice by immunization with MOC peptide $35-55$ on day 0 . Mice were treated by daily i.p. injection of $200 \mathrm{ng}$ recombinant murine IL-3 (IL-3) or PBS as control (PBS) from day 5-21 ( $n=15 /$ group). (A) Clinical symptoms of EAE (EAE score) are significantly higher in IL-3-treated mice. (B) Leukocyte subpopulations infiltrating the brain (left) and peripheral blood (right) were quantified by flow cytometry on day 22. (C) On day 22, splenocytes were restimulated with MOG peptide 35-55 or PBS as control for 3 days, and the level of IFN- $\gamma$, IL-17, and TNF were measured in the supernatant by ELISA. One out of 2 representative experiments is shown. Data are represented as mean \pm SEM, Student's $t$ test of PBS vs. IL-3: ${ }^{*} P \leq 0.05$.
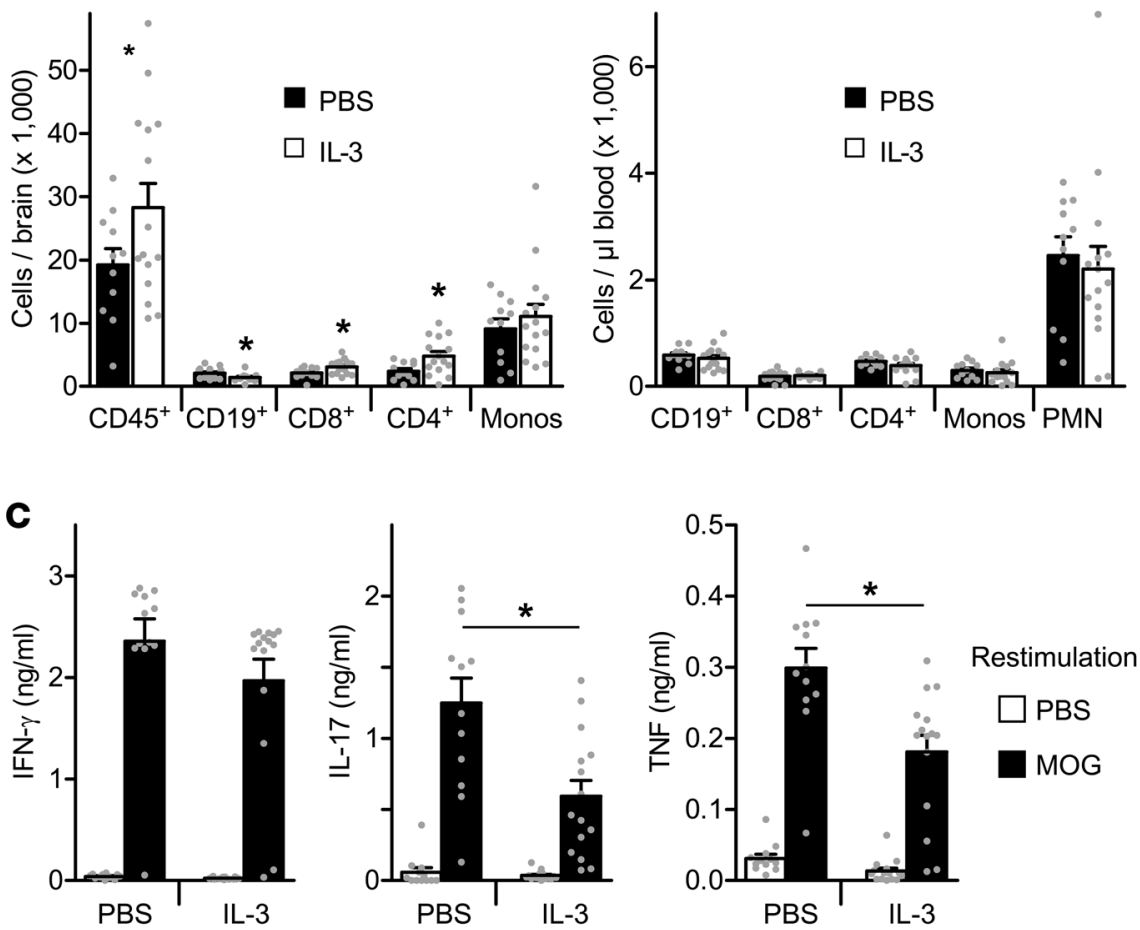

according to the genotype of the mice.

Impact of late blockade of IL-3 on development of EAE. As shown above, neutralization of IL-3 immediately after immunization with MOG peptide markedly improved development of EAE and the influx of leukocytes into the CNS. To analyze whether delayed treatment with anti-IL-3 antibodies is also beneficial, we started treatment on day 5 or day 10 after immunization and injected the antibody daily until day 20 When treatment was started on day 5, EAE symptoms were slightly reduced, with significant differences on day 10,13, and 16 (Supplemental Figure 6A). When neutralization of IL-3 was started on day 10, reduction of EAE symptoms/severity was detectable only on days $16-18$, and no differences were observed at the end of the experiment (Supplemental Figure 6B).

Exacerbation of EAE by injection of IL-3. Expression of murine IL-3 increased during the course of EAE, as shown above by restimulation of splenocytes and quantitative PCR of the CNS. However, the availability of IL-3 may still limit development of EAE. To further increase IL-3 levels in this model, we daily injected recombinant IL-3 (200 ng/mouse) from day 5-21. Administration of recombinant IL-3 significantly exacerbated clinical symptoms of EAE, as seen on days 17-22 (Figure 6A). Interestingly, there was no difference between the control group and the IL-3 group until day 14. Most likely, CD4 ${ }^{+} \mathrm{T}$ cells infiltrating the CNS during this phase of the disease produce saturating amounts of IL-3. Only after day 14, when the number of T cells and the cerebral IL-3 levels in the CNS decrease, injection of IL-3 may become relevant. Injection of IL-3 significantly increased CD4 ${ }^{+} \mathrm{T}$ cells, $\mathrm{CD}^{+} \mathrm{T}$ cells, and $\mathrm{B}$ cells in the CNS on day 22, while monocytes were only marginally increased. The numbers of T cells, B cells, or monocytes in the peripheral blood remained unchanged by treatment with recombinant IL-3 (Figure 6B). IL-3 also affected the cellular immune response against MOG peptide 35-55, as treatment of mice with IL-3 increased the antigen-specific release of IL-17 and TNF from splenocytes restimulated with MOG peptide 35-55 on day 22 (Figure 6C). In addition, we have analyzed whether recombinant IL-3 increases the cerebral expression of CCL2, CCL5, CXCL1, and E- and P-selectin (Supplemental Figure 7). MOG peptide-immunized mice were treated from day 0-10 by daily i.p. injection of $200 \mathrm{ng}$ recombinant murine IL-3 or PBS as control. On day 11, expression of CCL2, CCL5, E-selectin, and P-selectin in the brain was upregulated in IL-3-treated mice. 

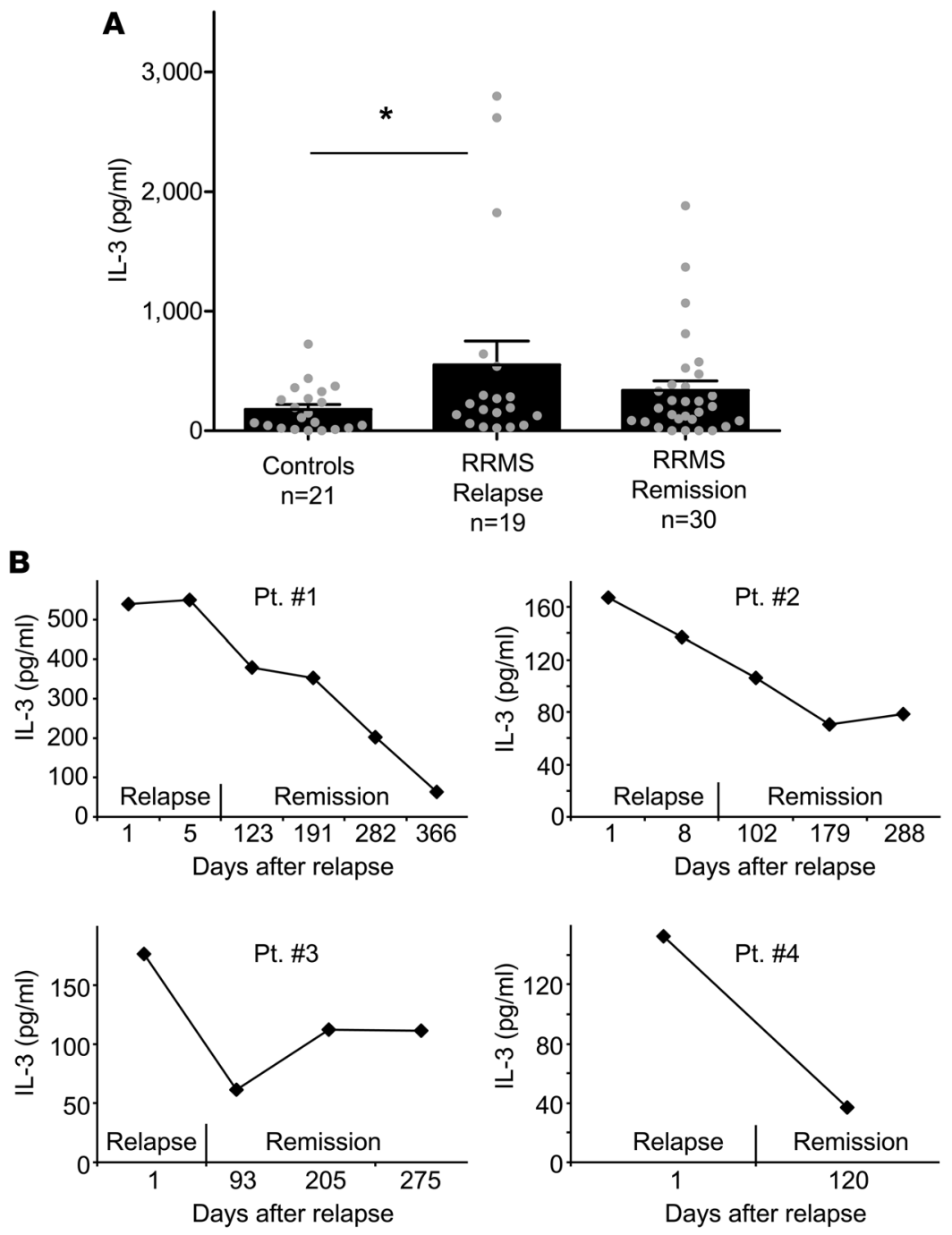

Figure 7. Expression of IL-3 in patients with MS and controls. (A) PBMC of patients with RRMS with active disease (relapse) or nonactive disease (remission) and PBMC of controls were stimulated with anti-CD3. After 3 days, IL-3 was quantified in the supernatant by ELISA. RRMS patients with active MS $(n=19)$ showed increased IL-3 secretion compared with patients with nonactive MS ( $n$ $=30$ ) and controls $(n=21)$. Data are represented as mean \pm SEM. Student's $t$ test of controls vs. active MS. ${ }^{*} P \leq 0.05$ (B) Four MS patients with active disease are depicted who stabilized over time and showed falling IL-3 values.

Taken together, our data show that injection of recombinant IL-3 results in exacerbation of EAE, while neutralization of IL-3 has a beneficial effect on EAE in mice.

Increased release of IL-3 from patients with MS. To study the production of IL-3 in patients with MS, we polyclonally activated peripheral blood mononuclear cells (PBMC) with anti-CD3 antibodies for 3 days and quantified the release of IL-3 into the supernatant by ELISA. Polyclonal stimulation of $\mathrm{T}$ cells from patients with RRMS resulted in increased IL-3 secretion in patients with a clinical relapse ( $n=19$, active disease) compared with patients in remission ( $n=30$, nonactive disease) or controls ( $n$ = 21) (Figure 7A). The IL-3 levels in untreated MS patients with active disease (IL-3 $=565 \mathrm{pg} / \mathrm{ml}, n=$ 5) were about $20 \%$ higher than in those treated with any immunomodulatory therapy (IL-3 $=481 \mathrm{pg} / \mathrm{ml}$, $n=14$ ). Also, in MS patients with inactive disease, IL-3 levels were somewhat higher in those untreated (IL-3 $=378 \mathrm{pg} / \mathrm{ml}, n=11$ ) than in those treated with any immunomodulatory therapy (IL-3 = 315

$\mathrm{pg} / \mathrm{ml}, n=19)$. The differences between treated and untreated patients were statistically not significant. Over time, patients with active disease who stabilized and had subsequently inactive disease showed falling IL-3 values (Figure 7B). Patient characteristics are provided in Supplemental Table 1.

\section{Discussion}

IL-3 belongs to the family of hematopoietic cytokines with 4 short $\alpha$-helices that also includes GM-CSF and IL-5 (7). All of these cytokines bind to a common $\beta$-receptor subunit and a unique $\alpha$-receptor subunit. While the role of GM-CSF for EAE is well documented (38-41), little is known about IL-3. Some reports describe expression of IL-3 in MS in humans and in murine encephalomyelitis, as well as demyelination and neurotoxicity, after overexpression of IL-3 (3, 4, 24, 28, 29). However, functional data regarding blockade of IL-3 in EAE are lacking. Although there are overlapping functions of GM-CSF and IL-3, GM-CSF seems to exacerbate EAE mainly by activation of monocytes (42). The impaired function of monocytes in GM-CSF-deficient mice is also responsible for the development of lung proteinosis that does not occur in IL-3-deficient mice (43). IL-3 acts on various cell types, including mast cells, basophils, monocytes, DCs, $\mathrm{B}$ cells, T cells, and endothelial cells (14-21). While the role of mast cells in EAE is somewhat controversial (44), other leukocyte subsets and transendothelial migration are clearly involved in development of encephalomyelitis (45-48). According to our data, the main producers of IL-3 in EAE are CD4 ${ }^{+} \mathrm{T}$ cells. In the spleen the release of IL-3 after restimulation with MOG peptide 35-55 is completely dependent on the presence of $\mathrm{CD}^{+} \mathrm{T}$ cells, and in the CNS, the expression of IL-3 closely correlates with the influx of $\mathrm{CD}^{+} \mathrm{T}$ cells. Expression of IL-3 in the CNS is markedly upregulated on day 14 after immunization with MOG peptide, while infiltrating T cells and IL-3 expression decrease in the CNS almost to baseline levels 
on day 20. Infiltrating monocytes remain high and contribute to CNS pathology, as shown by depletion of $\mathrm{CCR}^{+}$monocytes (48). Apart from T cells, other IL-3-producing cell types like B cells, basophils, neurons, or microglia may contribute to a MOG-independent production of IL-3 in the brain (9-13).

Using a blocking $\mathrm{mAb}$ against IL-3 and IL-3-deficient mice, we investigated the contribution of IL-3 to development of encephalomyelitis. IL- $3^{+/}$and IL- $3^{-/-}$mice developed significantly less symptoms of EAE compared with WT littermates. At the end of our observation period (day 17-20), IL- $3^{-/-}$mice showed more EAE symptoms than IL- $3^{+/-}$mice. While immune cell infiltrates in the brain were significantly reduced in both $\mathrm{IL}-3^{+/-}$and IL-3 $3^{-/-}$mice on day 11 , there was only a reduction in IL- $3^{+/-}$mice on day 20 . This suggests that compensatory mechanisms are active in IL- $3^{-/-}$mice, as also seen by an increased MOG-specific release of IL-17 in IL-3 ${ }^{-/-}$mice on day 20 . Treatment of mice with an anti-IL-3 antibody seemed to induce less counter-regulatory mechanisms, as clinical symptoms of EAE and immune cell infiltrations in the brain were reduced on day 11 and on day 20. Nevertheless, treatment with anti-IL-3 also slightly increased the MOG-specific release of cytokines on day 20. Delayed blockade of IL-3 from day 5-19 or day 10-19 was less effective. IL-3 seems to be a crucial and early inductor of inflammation and classical proinflammatory cytokines. In mice with collagen-induced arthritis, upregulation of IL-3 preceded the upregulation of classical proinflammatory cytokines in the synovium, and blockade of IL-3 significantly reduced immune cell infiltration and cytokine expression (22). In a model of sepsis, IL-3-deficient mice did not develop a cytokine storm (IL-1, IL-6, TNF) and showed a significantly better survival rate (9).

To better understand the mechanisms of how IL-3 affects development of EAE, we analyzed the impact of IL-3 on infiltration of various leukocyte subsets into the CNS on day 11-13 after immunization. Blockade of IL-3 markedly reduced the influx of $\mathrm{CD}^{+} \mathrm{T}$ cells, $\mathrm{CD} 8^{+} \mathrm{T}$ cells, and monocytes into the CNS, while the number of these cells in the peripheral blood remained unchanged. By adoptive transfer of CFSE-labeled leukocytes, we directly showed that IL-3 is involved in migration of leukocytes into the brain, independent of possible effects of IL-3 on peripheral priming or activation of leukocytes. Splenocytes were obtained from untreated MOG-immunized mice, labeled with CFSE and adoptively transferred into anti-IL-3 treated MOG-immunized mice. Treatment of the recipients with anti-IL-3 markedly reduced the migration of CFSE-labeled T cells, B cells, and monocytes into the brain. Adoptive transfer of CSFE-labeled leukocytes also revealed that monocytes have an almost 10-fold higher predisposition than $\mathrm{T}$ cells to migrate into the brain. This observation may explain why monocyte numbers remain high in the CNS until day 21, while T cells disappear after day 14

The impact of IL-3 on leukocyte migration into the brain is consistent with our finding that blockade of IL-3 significantly reduced the cerebral expression of E-selectin, P-selectin, and CCL5 (RANTES), which are known to direct leukocyte migration into the CNS $(34,35,37)$. IL-3 turned out to be the most potent cytokine for induction of RANTES by splenocytes, especially CD11b $\mathrm{LyC}^{+} \mathrm{CCR} 2^{+}$monocytes. IL-3 was previously described to induce a prolonged upregulation of P- and E-selectin on HUVEC, which was not achieved by other stimuli like LPS or TNF. However, LPS, TNF, and IL-1 $\beta$ were shown to upregulate the IL-3 receptor on endothelial cells and may thereby enhance transendothelial migration of leukocytes and breakdown of the blood brain barrier (49-52). In addition, local production of IL-3 in the CNS (e.g., by neurons or microglia, refs. 10-12) may also increase expression of adhesion molecules on leukocytes (e.g., on monocytes), facilitating their migration or increasing their half-life in the brain (20).

The involvement of IL-3 in EAE is further confirmed by our experiments with recombinant IL-3. Daily injection of IL-3 significantly increased development of EAE. However, EAE symptoms were only exacerbated in the late phase of the disease (day 17-22) but not in the early phase (day 9-16). One reason could be the high endogenous expression of IL-3 in the early phase by infiltrating T cells. Only when T cells disappear from the brain and IL-3 expression decreases, the effects of exogenous IL-3 may become detectable. Moreover, i.p. injection of IL-3 may also induce peripheral activation of leukocytes, thus facilitating their transendothelial migration, and could increase the survival of $\mathrm{T}$ and $\mathrm{B}$ cells, as shown previously in mice with lupus nephritis (23). Interestingly, injection of IL-3 mainly increased in the infiltration of CD4 ${ }^{+}$ and $\mathrm{CD}^{+} \mathrm{T}$ cells, indicating that migration of $\mathrm{T}$ cells into the $\mathrm{CNS}$ is, to a large degree, dependent on the presence of IL-3, while migration of monocytes into the CNS is less dependent on IL-3.

In patients with RRMS, we found a marked upregulation of IL-3 expression by T cells during episodes of relapse compared with healthy controls and with patients in remission. Clinical remission of MS did not completely normalize the IL-3 release, as IL-3 levels were still almost 2-fold increased. In addition, we show by serial measurements in individual patients that expression of IL-3 requires prolonged periods of 
time to decline after achievement of clinical remission. IL-3 levels were not significantly reduced in patients treated with immunomodulatory drugs (data not shown), suggesting that these medications do not reduce IL-3 expression to a major degree.

Together, our data indicate that IL-3 plays an important role in EAE and MS. IL-3 activates several leukocyte subsets and endothelial cells to release chemokines, proinflammatory cytokines, and adhesion molecules. IL-3 also plays a prominent role for migration of leukocytes, especially T cells, into the CNS. Blockade of IL-3 may therefore represent a promising new strategy for treatment of MS.

\section{Methods}

Induction of EAE. C57BL/6N (H-2 $\left.{ }^{\mathrm{b}}\right)$ mice were obtained from Charles River Laboratories. IL-3-deficient mice (C.129S2(B6)-I13<tm1G1li>/Rbrc) (53) were obtained from RIKEN BioResource Center and backcrossed for 6 generations into C57BL/6N. Heterozygous IL-3-deficient mice were crossbread to obtain WT, heterozygous, and homozygous mice. On day 0, female 8- to 12-week-old mice were immunized s.c. at both flanks with a total of $200 \mu \mathrm{l}$ solution containing $200 \mu \mathrm{g}$ MOG peptide 35-55 (MEVGWYRSPFSRVVHLYRNGK) in complete Freund's adjuvant (Sigma-Aldrich, F5506) containing $1 \mathrm{mg} \mathrm{M}$. butyricum (BD Biosciences, 264010). On days 0 and 2, mice were injected i.p. with $0.25 \mu \mathrm{g}$ pertussis toxin from B. pertussis (Sigma-Aldrich, P7208) dissolved in $200 \mu \mathrm{PBS}$ containing 1\% BSA. Individual mice were observed daily, and clinical scores were assessed by a blinded investigator as follows: $0=$ no clinical disease, $1=$ loss of tail tone only, $2=$ partial paralysis of hind legs, $3=$ complete paralysis of one or both hind legs, $4=$ complete paralysis of hind legs and partial or complete paralysis of one or both front legs, and $5=$ complete paralysis of all legs or death. Mice were kept under specific pathogen free (SPF) conditions in the core animal facility of the University of Regensburg Hospital and obtained water and food ad libitum with a 12-hour light/dark cycle.

Treatment of mice. Mice were treated as indicated in the figure legends by daily i.p. injection of $50 \mu \mathrm{g}$ purified anti-IL-3 antibody (clone MP2-8F8; Biozol), $50 \mu$ g purified and deglycosylated anti-IL-3 antibody (clone MP2-8F8) or the same amount of purified rat IgG (Jackson ImmunoResearch). Alternatively, mice were treated by daily i.p. injection of 200 ng recombinant murine IL-3 (Peprotech) or PBS as control. Deglycosylation of the anti-IL-3 antibody was performed overnight at $37^{\circ} \mathrm{C}$ with Peptide-N-Glycosidase F (New England Biolabs) using 2,000 U enzyme for $1 \mathrm{mg}$ antibody and subsequent dialysation against PBS. To verify complete deglycosylation by ELISA, plates were coated overnight with various concentrations of intact or deglycosylated anti-IL-3 antibody, washed with PBS/0.05\% Tween 20, blocked with Carbo-Free Blocking Solution, and detected with biotinylated Lens Culinaris Agglutinin followed by Streptavidin-HRP (all from Vector Laboratories).

Depletion of leukocyte subsets and culture of splenocytes. Splenocytes from immunized and nonimmunized mice were depleted of $\mathrm{CD}^{+}$and $\mathrm{CD} 8^{+} \mathrm{T}$ cells with magnetic beads directed against $\mathrm{CD} 4$ and $\mathrm{CD} 8$ and LD-columns (Miltenyi Biotec). To analyze the MOG peptide-specific release of cytokines, total splenocytes, or splenocytes depleted of a specific T cell subset ( 2 Mio cells/well) were cultured for 3 days with or without MOG peptide $(20 \mu \mathrm{g} / \mathrm{ml})$ in 96 -well flat-bottom plates in a total volume of $250 \mu 1$ medium (RPMI 1640 with $10 \%$ heat-inactivated FCS, penicillin/streptomycin, nonessential amino acids, $1 \mathrm{mM}$ sodium pyruvate, and $50 \mu \mathrm{M}$ 2-mercaptoethanol). The concentration of cytokines (IL-3, IFN- $\gamma$, GM-CSF, IL-6, TNF) in the culture supernatant was determined by ELISA (BioLegend and BD Biosciences). To measure release of RANTES (ELISA from R\&D Systems), total splenocytes, or splenocytes depleted of CD $11 b^{+}$, $\mathrm{Ly}_{6 \mathrm{C}^{+}}$, or CCR2 ${ }^{+}$cells were incubated for 24 or 48 hours with various cytokines (all $10 \mathrm{ng} / \mathrm{ml}$, obtained from Peprotech) in a volume of $200 \mu 1$.

Flow cytometry. Peripheral blood was drawn from the retroorbital venous plexus of anesthetized mice and anticoagulated with EDTA. To prepare single-cell suspensions of brain tissue, mice were sacrificed with carbon dioxide and transcardially perfused with $20 \mathrm{ml} \mathrm{NaCl} 0.9 \%$. Half of the brain was cut into small pieces and pressed through a $100-\mu \mathrm{m}$ cell strainer in a total volume of $1 \mathrm{ml}$. After centrifugation, cells were resuspended in $8 \mathrm{ml} \mathrm{40 \%} \mathrm{Percoll.} \mathrm{Percoll} \mathrm{(} 2 \mathrm{ml}, 80 \%$ ) was underlayed and centrifuged for $20 \mathrm{~min}$ at $700 \times g$. Cells in the interphase were recovered and washed once in RPMI medium with $10 \%$ FCS. The spinal cord was flushed out with PBS and prepared in the same manner as the brain to analyze the number of infiltrating leukocytes. For flow cytometry, cells were preincubated for 10 minutes on ice with Fc-block (clone $2.4 \mathrm{G} 2 ; 5 \mu \mathrm{g} / \mathrm{ml}$, eBioscience) and then stained with combinations of directly labeled antibodies for 25 minutes: anti-CD4 (clone RM4-5, Biolegend), CD8 (clone 53-6.7, Biolegend), anti-CD19 (clone eBio1D3, eBioscience), anti-CD11b (clone M1/70, eBioscience), anti-CD45 (cone 30-F11, BD Biosciences), and 
anti-Ly-6G (clone 1A8, BD Biosciences). Red blood cells were lysed with FACS-lysing solution (BD Biosciences) and samples analyzed on a FACSCantoII (BD Biosciences) with FACSDiva software. Leukocyte subsets were identified by their FSC-SSC properties and expression of surface markers. The number of cells was quantified using counting beads (Invitrogen).

For intracellular staining of cytokines, splenocytes were activated with PMA $(10 \mathrm{ng} / \mathrm{ml})$, ionomycine $(1 \mu \mathrm{g} / \mathrm{ml})$, and brefeldin A $(5 \mu \mathrm{g} / \mathrm{ml})$ for 3 hours. After staining with anti-CD4 (RM4-5) and anti-CD8 (clone 53-6.7) cells were treated with Fix-Perm and Perm-Wash solutions (BD Biosciences) incubated with Fc-block (clone 2.4G2;5 $\mu \mathrm{g} / \mathrm{ml}$ ) and stained intracellularly with antibodies against IL-3 (clone MP2-8F8, BD Biosciences),GM-CSF (clone MP1-22E9, BD Biosciences), IFN- $\gamma$ (clone XMG1.2, BD Biosciences), and IL-17a (clone 17B7, eBioscience).

Quantitative PCR. CNS tissue was snap-frozen in liquid nitrogen. Total RNA was isolated with RNeasy Mini Kit (Qiagen $\mathrm{GmbH}$ ) and reversely transcribed with oligo(dT) and M-MLV reverse transcriptase (Invitrogen). Real-time PCR was performed using QuantiTect SYBR Green PCR Kit (Qiagen GmbH) or TaqMan Gene Expression Assays (Applied Biosystems) and the Applied Biosystems ViiA 7 Real-Time PCR System. The following primers were used: CCL5 (RANTES), 5'-AGCAGCAAGTGCTCCAATCT-3' and 5'-GGGAAGCGTATACAGGGTCA-3'; CXCL1, 5'-ATCCAGAGCTTGAAGGTGTTG-3' and 5'-GTCTGTCTTCTTTCTCCGTTACTT-3'; E-selectin, 5'-CAAATCCCAGTCTGCAAAGC-3'and 5'-ACATTTCATGTTGCCCTGCT-3'; P-selectin, 5'GAGGGAAGAAAGCCAGACG-3' and 5'-GGCGTCCAGGAACCTTTT-3'; and $\beta$-actin, 5'-ACCCGCGAGCACAGCTTCTTTG-3' and 5'-ACATGCCGGAGCCGTTGTCGAC-3'. The following TaqMan probes were used: Mm01545399 (Hprt1), Mm00439631 (IL-3), Mm00439619 (IL-17a), Mm01290062 (GM-CSF), and Mm99999071 (IFN- $\gamma$ ). Data were analyzed with ViiA 7 Software (Applied Biosystems). The expression of each gene was calculated based on its standard curve and the CT of signal detection and is presented relative to expression of Hprt1 for IL-3, IL-17, IFN- $\gamma$, and GM-CSF or $\beta$-actin for CCL5 and CXCL1.

Patient characteristics. The characteristics of the individuals are presented in Supplemental Table 1. The mean age of the controls $(n=21)$ was 31 years, with $n=14$ females and $n=7$ males. The mean age of the group with RRMS with active disease $(n=19)$ was 35 years, with $n=13$ females and $n=6$ males. The mean duration since diagnoses of MS was made was 1.8 years and the Expanded Disability Status Scale (EDSS) was in mean 2.5. The mean age of the group with RRMS with inactive disease $(n=30)$ was 41 years, with $n=24$ females and $n=6$ males. The mean duration since diagnoses of MS was made was 7 years, and the EDSS was in mean 1.7.

Purification and activation of human PBMC. PBMC were isolated from heparinized blood samples on Lymphoprep density gradients (Nyegaard; $200 \mathrm{~g}, 25 \mathrm{~min}$, room temperature) as described (54). Cells were frozen at a density of $5 \times 10^{6} \mathrm{cells} / \mathrm{ml}$ in freezing media (FM) containing $40 \% \mathrm{FBS}, 10 \% \mathrm{DMSO}$, and $50 \%$ complete media (CM) consisting of RPMI 1640 supplemented with $2 \mathrm{mM}$ glutamine, $100 \mathrm{units} / \mathrm{ml}$ of penicillin, $100 \mu \mathrm{g} / \mathrm{ml}$ of streptomycin, and 10\% heat-inactivated FBS in liquid nitrogen. The cells were recovered by thawing in a $37^{\circ} \mathrm{C}$ water bath until the cells reached the melting point and then by adding 1 $\mathrm{ml} \mathrm{CM}$ per $5 \times 10^{6}$ cells 3 times every 5 minutes at room temperature. Thereafter, the cells were washed 3 times in CM and resuspended at a density of $1 \times 10^{6} / \mathrm{ml}$ in CM. The viability was $90 \%-95 \%$. PBMCs $(5 \times$ $10^{5}$ ) were cultured in $200 \mu 1$ medium (RPMI 1640 with $10 \%$ heat-inactivated FCS, penicillin/streptomycin, nonessential amino acids, $1 \mathrm{mM}$ sodium pyruvate, and $50 \mu \mathrm{M} 2$-mercaptoethanol) per well in triplicate and stimulated with anti-CD3 (5 $\mu \mathrm{g} / \mathrm{ml}$, clone: OKT3, eBiosciences) for 3 days. The supernatant was collected, and the IL-3 concentration was measured by ELISA using newly generated monoclonal antibodies against IL-3 (clone 13 and clone 11). ELISA plates were coated with $5 \mu \mathrm{g} / \mathrm{ml}$ clone 13 overnight at $4^{\circ} \mathrm{C}$, washed and blocked with PBS/1\% BSA. The supernatant was applied for 1 hour at room temperature, and bound IL-3 was detected with $0.4 \mu \mathrm{g} / \mathrm{ml}$ HRP-labeled clone 11 diluted in PBS/1\% BSA. Washing steps were performed with PBS/0.05\% Tween 20 . The ELISA did not show any crossreactivity with closely related cytokines like GM-CSF or IL-5 and had a sensitivity below $10 \mathrm{pg} / \mathrm{ml}$ IL-3.

Statistics. Data are represented as mean. Error bars indicate \pm SEM. Significance was calculated with a one-sided Students $t$ test or with one-sided ANOVA tests. A $P$ value less than 0.05 was considered significant.

Study approval. The EAE experiments were approved by the governmental administration of the Oberpfalz (54-2352 1-35/12). The analysis of human blood samples was approved by the Ethics Committee of the University of Regensburg (Approval number 12-101-0004). All patients with MS and controls gave written consent before blood drawing. 


\section{Author Contributions}

$\mathrm{KR}, \mathrm{HB}, \mathrm{RW}$ and MM contributed to design of experiments, acquisition, analysis and interpretation of data and writing of the paper. SH, FH, CR, YT, GS, MRG, SK, NG contributed to acquisition, analysis and interpretation of data. DH contributed to acquisition, and analysis of data.

\section{Acknowledgments}

This work was supported by grants from the Deutsche Forschungsgemeinschaft to HB and MM (21-98) and Regensburg Center for Interventional Immunology (RCI) to RW, HB, and MM. We thank Sophia Neumayer for technical assistance.

Address correspondence to: Matthias Mack, University Hospital Regensburg, Franz-Josef-Strauss Allee 11, 93042 Regensburg, Germany. Phone: 49.941.9447315; E-mail: matthias.mack@klinik.uni-regensburg.de.

1. Hofstetter HH, Karulin AY, Forsthuber TG, Ott PA, Tary-Lehmann M, Lehmann PV. The cytokine signature of MOG-specific CD4 cells in the EAE of C57BL/6 mice. J Neuroimmunol. 2005;170(1-2):105-114.

2. Karulin AY, Quast S, Hesse MD, Lehmann PV. Neuroantigen-Specific CD4 Cells Expressing Interferon- $\gamma$ (IFN- $\gamma$ ), Interleukin (IL)-2 and IL-3 in a Mutually Exclusive Manner Prevail in Experimental Allergic Encephalomyelitis (EAE). Cells. 2012;1(3):576-596.

3. Tran EH, Prince EN, Owens T. IFN-gamma shapes immune invasion of the central nervous system via regulation of chemokines. J Immunol. 2000;164(5):2759-2768.

4. Lyons JA, Zhao ML, Fritz RB. Pathogenesis of acute passive murine encephalomyelitis II. Th1 phenotype of the inducing population is not sufficient to cause disease. J Neuroimmunol. 1999;93(1-2):26-36.

5. Morris MM, Dyson H, Baker D, Harbige LS, Fazakerley JK, Amor S. Characterization of the cellular and cytokine response in the central nervous system following Semliki Forest virus infection. J Neuroimmunol. 1997;74(1-2):185-197.

6. Natarajan C, Sriram S, Muthian G, Bright JJ. Signaling through JAK2-STAT5 pathway is essential for IL-3-induced activation of microglia. Glia. 2004;45(2):188-196.

7. Broughton SE, et al. The GM-CSF/IL-3/IL-5 cytokine receptor family: from ligand recognition to initiation of signaling. Immunol Rev. 2012;250(1):277-302.

8. Dotsika EN, Sanderson CJ. Interleukin-3 production as a sensitive measure of T-lymphocyte activation in the mouse. Immunology. 1987;62(4):665-668.

9. Weber GF, et al. Interleukin-3 amplifies acute inflammation and is a potential therapeutic target in sepsis. Science. 2015;347(6227):1260-1265.

10. Konishi Y, Kamegai M, Takahashi K, Kunishita T, Tabira T. Production of interleukin-3 by murine central nervous system neurons. Neurosci Lett. 1994;182(2):271-274.

11. Appel K, Honegger P, Gebicke-Haerter PJ. Expression of interleukin-3 and tumor necrosis factor-beta mRNAs in cultured microglia. J Neuroimmunol. 1995;60(1-2):83-91.

12. Gebicke-Haerter PJ, et al. Rat microglial interleukin-3. J Neuroimmunol. 1994;50(2):203-214.

13. Schroeder JT, Chichester KL, Bieneman AP. Human basophils secrete IL-3: evidence of autocrine priming for phenotypic and functional responses in allergic disease. J Immunol. 2009;182(4):2432-2438.

14. Lantz CS, et al. Role for interleukin-3 in mast-cell and basophil development and in immunity to parasites. Nature. 1998;392(6671):90-93.

15. Denzel A, et al. Basophils enhance immunological memory responses. Nat Immunol. 2008;9(7):733-742.

16. Palacios R, Garland J. Distinct mechanisms may account for the growth-promoting activity of interleukin 3 on cells of lymphoid and myeloid origin. Proc Natl Acad Sci U S A. 1984;81(4):1208-1211.

17. Palacios R, Henson G, Steinmetz M, McKearn JP. Interleukin-3 supports growth of mouse pre-B-cell clones in vitro. Nature. 1984;309(5964):126-131.

18. Kuribara R, et al. Two distinct interleukin-3-mediated signal pathways, Ras-NFIL3 (E4BP4) and Bcl-xL, regulate the survival of murine pro-B lymphocytes. Mol Cell Biol. 1999;19(4):2754-2762.

19. Storozynsky E, Woodward JG, Frelinger JG, Lord EM. Interleukin-3 and granulocyte-macrophage colony-stimulating factor enhance the generation and function of dendritic cells. Immunology. 1999;97(1):138-149.

20. Elliott MJ, Vadas MA, Cleland LG, Gamble JR, Lopez AF. IL-3 and granulocyte-macrophage colony-stimulating factor stimulate two distinct phases of adhesion in human monocytes. J Immunol. 1990;145(1):167-176.

21. Didichenko SA, Spiegl N, Brunner T, Dahinden CA. IL-3 induces a Pim1-dependent antiapoptotic pathway in primary human basophils. Blood. 2008;112(10):3949-3958.

22. Brühl H, et al. Important role of interleukin-3 in the early phase of collagen-induced arthritis. Arthritis Rheum. 2009;60(5):13521361.

23. Renner K, et al. IL-3 contributes to development of lupus nephritis in MRL/lpr mice. Kidney Int. 2015;88(5):1088-1098.

24. Baranzini SE, et al. Transcriptional analysis of multiple sclerosis brain lesions reveals a complex pattern of cytokine expression. J Immunol. 2000;165(11):6576-6582.

25. Djaldetti R, Achiron A, Ziv I, Djaldetti M, Melamed E, Fishman P. IL-3-LA production by mononuclear cells of patients with multiple sclerosis: effect of treatment with intravenous immunoglobulins. Immunol Invest. 1995;24(5):765-773.

26. Huberman M, Shalit F, Roth-Deri I, Gutman B, Kott E, Sredni B. Decreased IL-3 production by peripheral blood mononuclear cells in patients with multiple sclerosis. J Neurol Sci. 1993;118(1):79-82. 
27. Kovalchin J, et al. Results of a phase I study in patients suffering from secondary-progressive multiple sclerosis demonstrating the safety of the amino acid copolymer PI-2301 and a possible induction of an anti-inflammatory cytokine response. $J$ Neuroimmunol. 2010;225(1-2):153-163.

28. Chiang CS, Powell HC, Gold LH, Samimi A, Campbell IL. Macrophage/microglial-mediated primary demyelination and motor disease induced by the central nervous system production of interleukin-3 in transgenic mice. J Clin Invest. 1996;97(6):1512-1524.

29. Chavany C, Vicario-Abejón C, Miller G, Jendoubi M. Transgenic mice for interleukin 3 develop motor neuron degeneration associated with autoimmune reaction against spinal cord motor neurons. Proc Natl Acad Sci U S A. 1998;95(19):11354-11359.

30. Zhao ML, Xia JQ, Fritz RB. Interleukin-3 and encephalitogenic activity of SJL/J myelin basic protein-specific T cell lines. $J$ Neuroimmunol. 1993;43(1-2):69-78.

31. Cockayne DA, Bodine DM, Cline A, Nienhuis AW, Dunbar CE. Transgenic mice expressing antisense interleukin-3 RNA develop a B-cell lymphoproliferative syndrome or neurologic dysfunction. Blood. 1994;84(8):2699-2710.

32. Kamegai M, et al. Interleukin 3 as a trophic factor for central cholinergic neurons in vitro and in vivo. Neuron. 1990;4(3):429436

33. Kuerten S, Javeri S, Tary-Lehmann M, Lehmann PV, Angelov DN. Fundamental differences in the dynamics of CNS lesion development and composition in MP4- and MOG peptide 35-55-induced experimental autoimmune encephalomyelitis. Clin Immunol. 2008;129(2):256-267.

34. dos Santos AC, Barsante MM, Arantes RM, Bernard CC, Teixeira MM, Carvalho-Tavares J. CCL2 and CCL5 mediate leukocyte adhesion in experimental autoimmune encephalomyelitis--an intravital microscopy study. J Neuroimmunol. 2005;162(12):122-129.

35. Glass WG, Hickey MJ, Hardison JL, Liu MT, Manning JE, Lane TE. Antibody targeting of the CC chemokine ligand 5 results in diminished leukocyte infiltration into the central nervous system and reduced neurologic disease in a viral model of multiple sclerosis. J Immunol. 2004;172(7):4018-4025

36. Roy M, Richard JF, Dumas A, Vallières L. CXCL1 can be regulated by IL-6 and promotes granulocyte adhesion to brain capillaries during bacterial toxin exposure and encephalomyelitis. J Neuroinflammation. 2012;9:18

37. Vilela MC, et al. The chemokine CCL5 is essential for leukocyte recruitment in a model of severe Herpes simplex encephalitis Ann N Y Acad Sci. 2009;1153:256-263.

38. Codarri L, et al. ROR $\gamma$ t drives production of the cytokine GM-CSF in helper T cells, which is essential for the effector phase of autoimmune neuroinflammation. Nat Immunol. 2011;12(6):560-567.

39. El-Behi M, et al. The encephalitogenicity of $\mathrm{T}(\mathrm{H}) 17$ cells is dependent on IL-1- and IL-23-induced production of the cytokine GM-CSF. Nat Immunol. 2011;12(6):568-575.

40. McQualter JL, et al. Granulocyte macrophage colony-stimulating factor: a new putative therapeutic target in multiple sclerosis. J Exp Med. 2001;194(7):873-882.

41. Ponomarev ED, Shriver LP, Maresz K, Pedras-Vasconcelos J, Verthelyi D, Dittel BN. GM-CSF production by autoreactive T cells is required for the activation of microglial cells and the onset of experimental autoimmune encephalomyelitis. $J$ Immunol. 2007;178(1):39-48.

42. Croxford AL, et al. The Cytokine GM-CSF Drives the Inflammatory Signature of CCR2+ Monocytes and Licenses Autoimmunity. Immunity. 2015;43(3):502-514.

43. Nishinakamura R, et al. Mice deficient for the IL-3/GM-CSF/IL-5 beta c receptor exhibit lung pathology and impaired immune response, while beta IL3 receptor-deficient mice are normal. Immunity. 1995;2(3):211-222.

44. Costanza M, Colombo MP, Pedotti R. Mast cells in the pathogenesis of multiple sclerosis and experimental autoimmune encephalomyelitis. Int J Mol Sci. 2012;13(11):15107-15125.

45. Yoshizaki A, et al. Regulatory B cells control T-cell autoimmunity through IL-21-dependent cognate interactions. Nature. 2012;491(7423):264-268.

46. Weber MS, et al. B-cell activation influences T-cell polarization and outcome of anti-CD20 B-cell depletion in central nervous system autoimmunity. Ann Neurol. 2010;68(3):369-383.

47. Kap YS, et al. Late B cell depletion with a human anti-human CD20 IgG1 $\kappa$ monoclonal antibody halts the development of experimental autoimmune encephalomyelitis in marmosets. J Immunol. 2010;185(7):3990-4003.

48. Mildner A, et al. CCR2+Ly-6Chi monocytes are crucial for the effector phase of autoimmunity in the central nervous system. Brain. 2009;132(Pt 9):2487-2500.

49. Khew-Goodall Y, et al. Chronic expression of P-selectin on endothelial cells stimulated by the T-cell cytokine, interleukin-3. Blood. 1996;87(4):1432-1438.

50. Korpelainen EI, et al. The receptor for interleukin 3 is selectively induced in human endothelial cells by tumor necrosis factor alpha and potentiates interleukin 8 secretion and neutrophil transmigration. Proc Natl Acad Sci U S A. 1993;90(23):11137-11141.

51. Brizzi MF, et al. Interleukin 3 stimulates proliferation and triggers endothelial-leukocyte adhesion molecule 1 gene activation of human endothelial cells. J Clin Invest. 1993;91(6):2887-2892.

52. Obermeier B, Daneman R, Ransohoff RM. Development, maintenance and disruption of the blood-brain barrier. Nat Med. 2013;19(12):1584-1596.

53. Mach N, et al. Involvement of interleukin-3 in delayed-type hypersensitivity. Blood. 1998;91(3):778-783.

54. Riedhammer C, Halbritter D, Weissert R. Peripheral Blood Mononuclear Cells: Isolation, Freezing, Thawing, and Culture. Methods Mol Biol. 2016;1304:53-61. 